\title{
Multivariate epidemiologic analysis of type 2 diabetes mellitus risks in the Lebanese population
}

\author{
Michella Ghassibe-Sabbagh ${ }^{1}$, Mary Deeb ${ }^{1 \dagger}$, Angelique K Salloum ${ }^{1 \dagger}$, Francis Mouzaya ${ }^{1}$, Marc Haber ${ }^{1}$, Yasser Al-Sarraj ${ }^{2}$, \\ Youssef Chami ${ }^{1}$, Yasmine Akle ${ }^{3}$, Kamal Hirbli ${ }^{1}$, Rita Nemr ${ }^{1}$, Rechdi Ahdab ${ }^{1}$, Daniel E Platt ${ }^{4}$, Antoine B Abchee ${ }^{5}$, \\ Hatem El-Shanti ${ }^{2}$ and Pierre A Zalloua ${ }^{1,6^{*}}$
}

\begin{abstract}
Background: The burden of diabetes in Lebanon requires well-targeted interventions for screening type 2 diabetes mellitus (T2DM) and prediabetes and prevention of risk factors. Newly recruited 998 Lebanese individuals, in addition to 7,292 already available, were studied to investigate the prevalence of diabetes, prediabetes and their associated risk factors.

Methods: Participants had fasting blood sugar and glycohemoglobin tests in addition to a lipid profile. Clinical and demographic information were obtained from a detailed questionnaire. The relationship between T2DM, its risk factors, and its complications were tested. Comparisons of these risk factors among diabetics, healthy, and coronary artery disease (CAD) patients were performed.

Results: The prevalence of T2DM significantly increased with increasing BMI $(p<0.0001)$. Exercise activity level negatively correlated with the disease $(p=0.002)$, whereas the prevalence of T2DM $(p<0.0001)$ and CAD family history $(p=0.006)$ positively correlated with the affection status. The mean levels of triglycerides and LDL-C were significantly higher in diabetics $(1.87 ; 1.35)$ compared to individuals with prediabetes $(1.63 ; 1.26)$ and unaffected controls (1.49; 1.19). People with T2DM showed a significant decrease in HDL-C levels. A strong correlation of overall hyperlipidemia with the diabetes affection status was shown $(p<0.0001)$. Other comorbid factors such as hypertension ( $p<0.0001)$ and self-reported obesity $(p<0.0001)$ were highly associated with T2DM and prediabetes. Reproductive health of women showed a strong correlation between giving birth to a baby with a high weight and the occurrence of T2DM and prediabetes later in life $(p<0.0001)$. Retinopathy and peripheral neuropathy were significantly correlated with diabetes and prediabetes $(p<0.0001)$.
\end{abstract}

Conclusions: The present study shows an alarming prevalence of diabetes and prediabetes in the studied subgroups representative of the Lebanese population.

Keywords: Type 2 diabetes, Prediabetes, Lebanon, Risk factors, Hyperlipidemia, Coronary artery disease

\section{Background}

According to the International Diabetes Federation (IDF), 32.8 million people or $9.1 \%$ of the adult population in the Middle East and North Africa Region (MENA) had diabetes in 2011 [1]. A further 24 million people, or $6.7 \%$ of the population, are at high risk of diabetes from impaired glucose tolerance. Six of the 10 countries with

\footnotetext{
* Correspondence: pierre.zalloua@lau.edu.lb

${ }^{\dagger}$ Equal contributors

'Lebanese American University, School of Medicine, Beirut 1102 2801, Lebanon

${ }^{6}$ Harvard School of Public Health, Boston, MA 02215, USA

Full list of author information is available at the end of the article
}

the highest prevalence of diabetes in the world are from the MENA Region: United Arab Emirates (18.7\%), Saudi Arabia (16.8\%), Bahrain (15.4\%), Kuwait (14.6\%), Oman (13.4\%), and Lebanon (7.7\%). By 2025, the number of people with diabetes is expected to more than double in these regions. According to the World Health Organization, the age-standardized mortality rate from cardiovascular disease and diabetes per year was estimated to be 224 in 2008 in Lebanon, which is 1.2 times higher than cancer mortality rate.

In spite of the high estimates of diabetes prevalence in the region, the healthcare expenditures due to diabetes

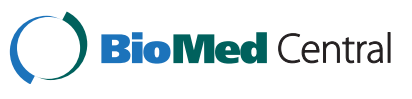


account for $2.3 \%$ of the total global figure and many governments remain largely unaware of the current magnitude and future burden of diabetes in their societies [1]. T2DM in Lebanon would be better managed if we had a global overview on the prevalence of prediabetes and diagnosed and undiagnosed diabetes mellitus, coupled to an estimation of risk factors such as physical inactivity, obesity, hyperlipidemia, and gestational diabetes mellitus (GDM). In addition, T2DM and Coronary Artery Disease (CAD) frequently coexist and are major components of the public health and economic burden worldwide. An epidemiologic study targeting risk factors such as physical inactivity, smoking, and alcohol consumption can therefore help guiding a proportionate public health response to the epidemic of diabetes and CAD. Susceptibility to these complex diseases is strongly influenced by common environmental factors, but how these factors act in the Lebanese population remains largely unknown.

In order to leverage the genetic information from prior studies in this laboratory, it is desirable to pool prior CAD data with data collected specifically for T2DM. A difficulty is that the enrollment criteria were strikingly different. The CAD study subjects were all enrolled from a pool of catheterized patients. Since catheterization is an invasive procedure, all subjects, whether or not they ultimately showed luminal narrowing, had to showsufficient cause for the catheterization according to clinical indications and behavior. The T2DM study enrollment occurred at multiple clinical sites where recruitment was advertised. This enrollment included selection of cases versus controls. In order to associate genetic markers with demographics and disease in a pooled set of data, the impact of the enrollment criteria was characterized.

The aims of this study are: (1) to estimate the prevalence of prediabetes, diagnosed and undiagnosed diabetes in the Lebanese population age 55 or older, (2) to investigate and identify the risk factors of T2DM and CAD in the Lebanese population and, (3) to estimate the inferred risk of known factors to T2DM and CAD patients. Results from this study will help policy makers and health practitioners in promoting well-targeted prevention programs to minimize the burden of diabetes mellitus in developing countries.

\section{Methods}

\section{Study population}

The study consisted of two phases. In the first phase of the project we actively recruited 998 subjects in 2012 specifically to survey the prevalence of diabetes and its risk factors among the Lebanese population. In the second phase we selected $991 \mathrm{CAD}$ cases from an existing database that consisted of 7,292 subjects recruited between 2007 and 2013 to study CAD and associated diseases such as T2DM and hypertension (FGENTCARD - Functional Genomic Diagnostic Tools for Coronary Artery Disease). The combined phase 1 and phase 2 datasets were used to study the association of risk factors with T2DM and CAD and to estimate the inferred risk of known factors to T2DM and CAD.

An additional CAD-free 1,330 subjects from the FGEN TCARD database were combined with the subjects from Phase 1 to further investigate the prevalence of T2DM in the Lebanese population.

\section{Surveyed population through targeted T2DM campaigns (Phase 1)}

In this phase 998 Lebanese adult subjects were recruited through two targeted advertisement campaigns for volunteers over the age of 55 to have their blood tested for diabetes. The first campaign was conducted in the suburbs of Beirut, the capital of Lebanon, with the collaboration of the Lebanese American University Medical Center. The second advertisement campaign was conducted in North Lebanon where volunteer recruitment was done in five villages with the help of endocrinologists and local social workers. Research was carried out in compliance with the Helsinki Declaration and with the approval of the LAU Institutional Review Board and local ethics committees on human research (Reference number SMPZ08072010-4). All participants signed an approved informed consent. The consent form stipulated that the participant agreed to be interviewed and to give a blood sample to be used for DNA analysis, as well as glycated hemoglobin (HbA1C), fasting blood sugar (FBS), and lipid profile measurements.

\section{FGENTCARD population (Phase 2)}

991 subjects, of which $31.9 \%$ were diabetics and $68.1 \%$ were non diabetics were selected from a database that included 7,292 subjects that were recruited between 2007 and 2013 for inclusion in the FGENTCARD database. Detailed clinical and demographic information have been previously described [2] (Additional file 1). 406 out of the 991 participants had $>50 \%$ stenosis in at least one vessel and were designated as severe CAD patients, 207 had stenosis $\leq 50 \%$ in at least one vessel and were designated as moderate CAD patients, and 378 had $0 \%$ stenosis and were classified as controls. Individuals were chosen to match with the T2DM surveyed populations for sex (35.6\% of males and $64.4 \%$ of females) and mean age (63.9 for severe stenosis; 65.9 for moderate and mild stenosis and 63.7 for unaffected controls).

The subjects from Phase 1 were compared to a stenosisfree population of 1,330 clinically well-characterized subjects selected from the FGENTCARD database. From the 1,330 selected controls, 664 were more than 55 years old. 
Blood samples collection and laboratory test performance In order to measure the height and weight of all participants, a calibrated mass was placed on a scale. The known mass value was compared to the scale reading and the percent error was calculated to determine the acceptability of the balance or scale prior to height and weight measurements. The height and weight were used to calculate the body mass index (BMI). The blood samples were collected by well-trained phlebotomists.

For the surveyed population, blood samples were collected for Glycated Hemoglobin 1C (HbA1C) testing, FBS and lipid profile assays. HbA1C, Fasting Blood Sugar (FBS) and lipid profile assays were performed on COBAS INTEGRA 400 Plus as follows: HbA1c levels were determined using an immunoturbidimetric assay, FBS was measured via an enzymatic reference method using the hexokinase, and the lipid panel (total cholesterol (TC), triglycerides, HDL-cholesterol (HDL-C), and LDL-cholesterol (LDL-C)) was measured according to the absorbance photometry principle via enzymatic colorimetric methods.

For the FGENTCARD population, cardiologists performing the coronary angiography collected a $20 \mathrm{~mL}$ blood sample from the peripheral femoral artery of patients. Annotations were coded from medical charts according to the study protocol, which included results of laboratory tests, prescribed medications, and presence of other diseases and conditions.

\section{Measurement of variables}

BMI was calculated according to standard measurements. A BMI of $25-30 \mathrm{~kg} / \mathrm{m}^{2}$ indicated overweight and a BMI of $\geq 30 \mathrm{~kg} / \mathrm{m}^{2}$ was an indicator of obesity. FBS was categorized according to glucose level: $70-99 \mathrm{mg} / \mathrm{dL}$, normal fasting glucose; $100-125 \mathrm{mg} / \mathrm{dL}$, impaired fasting glucose or prediabetes; and $\geq 126 \mathrm{mg} / \mathrm{dL}$, diabetes. An HDL-C level $<35 \mathrm{mg} / \mathrm{dL}$ was set as an increased risk of T2DM. For LDL-C, TC, and triglycerides, the threshold levels for an increased T2DM risk were $\geq 130 \mathrm{mg} / \mathrm{dL}, \geq 200 \mathrm{mg} / \mathrm{dL}$, and $\geq 250 \mathrm{mg} / \mathrm{dL}$ respectively in line with standard definitions of hyperlipidemia.

Participants were considered hypertensive if blood pressure is at or above $140 / 90 \mathrm{mmHg}$ or if they were on antihypertensive drugs. Participants were diagnosed with T2DM if they were clinically documented diabetic patients on medication (oral hypoglycemic agent or insulin), or presented with a level of HbA1C of $\geq 6.5 \%$ in line with the American Diabetes Association (ADA) definition of type 2 diabetes mellitus diagnosis [3]. Individuals with an $\mathrm{HbA1C}$ ranging from $5.7 \%$ to $6.4 \%$ were considered as prediabetics with an increased risk of developing diabetes in the future. Individuals with an $\mathrm{HbA} 1 \mathrm{c} \leq 5.6 \%$. were labeled as healthy non-diabetic. Participants were considered hyperlipidemic if they had clinically documented hyperlipidemia with medication intake, or presented with a level of TC, triglycerides, or LDL-C above the threshold. A family history was positive when the condition was present in a parent, sibling, or second degree relative.

\section{Statistical analysis}

Data analysis was conducted with the statistical software package "Statistical Package for Social Sciences" (SPSS) for windows, version 20 , and the glm package from $R$ version 3.0.2 [4]. Chi square test is used to assess the association between two categorical variables and ANOVA for continuous variables. Odds ratios were obtained using multinomial logistic regression. For HDL-C, odds ratios were calculated using the thresholds of HDL-C $<35 \mathrm{mg} / \mathrm{dL}$ and of TC/HDL-C ratio $\geq 4 \mathrm{mg} / \mathrm{dL}$ as increased risks for T2DM and CAD respectively. A $p$ value of 0.05 was considered to indicate statistical significance.

Impact of enrollment was estimated by applying logistic regression to predict diagnosis of CAD and T2DM based solely on study population, where the data were re-partitioned for this analysis ( $1=$ CAD study enrollment, 5,359 subjects; $2=$ T2DM enrollment, 998 subjects, all of both groups 55 years old or older). Only 177 T2DM enrolled subjects showed knowledge of CAD state. Enrollment criteria associations were also explored for behavioral components (active lifestyle and smoking), as well as clinical variables (diagnoses of hypertension, hyperlipidemia, high triglycerides, BMI - threshold of 30, and HDL). Second, association of enrollment population and behavior with clinical variables was assessed. Third, an association test of how metabolic syndrome varies with diagnosis of T2DM and CAD was performed. Fourth, interactions of triglycerides with T2DM, and the impact of T2DM on CAD, were examined. These results are non-tabulated due to variable format and test structure.

\section{Results}

In the surveyed population (Phase 1) 354 (35.6\%) were males and $639(64.4 \%)$ were females (Table 1). The mean age of the control group is 65 years old which diminishes the possibility of developing T2DM since the mean age of onset of T2DM in our cohort was 54.6 years old $( \pm 12.4)$. The prevalence of T2DM significantly increased with increasing BMI $(\mathrm{p}<0.0001)$ (Table 1).

Out of the 991 subjects selected in phase 2, 353 (35.6\%) were males and 638 (64.4\%) were females (Table 2). The mean age of the control group is 64 years old $( \pm 10.5)(\mathrm{n}=378)$ compared to 66 years old $( \pm 9.9)$ in the moderately affected group $(n=207)$, and 64 years old $( \pm 11.3)$ in the severely affected group $(n=406)$. Exercise activity level negatively correlated with the disease $(p=0.002)$, whereas the prevalence of T2DM $(p<0.0001)$ and CAD family history $(\mathrm{p}=0.006)$ positively correlated with the affection status (Table 2). 
Table 1 Distribution in the surveyed population of different factors by T2DM diagnosis status

\begin{tabular}{|c|c|c|c|c|c|}
\hline & & T2DM ca & ories & & \\
\hline & Diabetics $n=407$ & Prediabetics $n=207$ & Non-diabetic $n=379$ & Total $n=993$ & $p$ value \\
\hline & No. (\%) & No. (\%) & No. (\%) & & \\
\hline Gender & & & & & 0.4 \\
\hline Male & $154(37.8)$ & $68(32.9)$ & $132(34.8)$ & & \\
\hline Female & $253(62.2)$ & $139(67.1)$ & $247(65.2)$ & & \\
\hline Age (Years) mean (SD) & $64(11.4)$ & $66(9.9)$ & $65(12.3)$ & & 0.09 \\
\hline Age of onset (Years) mean (SD) & $55(12.4)$ & $60(11.4)$ & NA & & 0.03 \\
\hline Body Mass Index, mean (SD) & $29.1(5.4)$ & $28.6(5.1)$ & $27.3(4.4)$ & & $<0.0001$ \\
\hline Exercise activity level & & & & & 0.9 \\
\hline Non-active & $248(62.0)$ & $116(56.9)$ & $215(60.4)$ & & \\
\hline Moderate activity & $58(14.5)$ & $33(16.2)$ & $48(13.5)$ & & \\
\hline Heavy activity & $94(23.5)$ & $55(27.0)$ & $93(26.1)$ & & \\
\hline Smoking & & & & & 0.2 \\
\hline Never smoker & $179(44.8)$ & $103(50.5)$ & $190(53.2)$ & & \\
\hline Former smoker & $92(23.0)$ & $43(21.1)$ & $70(19.6)$ & & \\
\hline Current smoker & $129(32.3)$ & $58(28.4)$ & $97(27.2)$ & & \\
\hline Alcohol consumption & & & & & 0.003 \\
\hline Never drinker & $276(69.0)$ & $132(64.7)$ & $219(61.3)$ & & \\
\hline Less than 7 drinks per week & $118(29.5)$ & $70(34.3)$ & 119 (33.3) & & \\
\hline More than 7 drinks per week & $6(1.5)$ & $2(1.0)$ & $19(5.3)$ & & \\
\hline Family history of T2DM & & & & & \\
\hline Yes & $267(67.9)$ & $87(44.4)$ & $158(47.7)$ & & $<0.0001$ \\
\hline No & $126(32.1)$ & $109(55.6)$ & $173(52.3)$ & & \\
\hline Consanguinity & & & & & 0.96 \\
\hline Yes & $69(17.5)$ & $36(18.3)$ & $58(17.4)$ & & \\
\hline No & $325(82.5)$ & $161(81.7)$ & $276(82.6)$ & & \\
\hline
\end{tabular}

Abbreviation: T2DM Type 2 diabetes mellitus, SD Standard deviation.

To counter the recruitment bias in our selection criteria through the two T2DM advertised campaigns where it is expected that more diabetics would likely participate, we selected an additional 1,330 subjects stenosis-free from the FGENTCARD population. Out of these 687 (51.7\%) were males and $643(48.3 \%)$ were females (Table 3). The mean age of the control group is 55 years old $( \pm 11.9)$ compared to the mean age of the diabetics which is 58 years old $( \pm 11.6)$. According to their medical records, $20.5 \%$ of the participants had type 2 diabetes, this percentage increased to $23.6 \%$ when the calculations included people above 55 years old (Table 4). Studying risk factors by T2DM diagnostic status confirmed a significant association of activity level, BMI, triglycerides, overall hyperlipidemia, positive T2DM family history, and hypertension with T2DM (Table 3). Although HDL-C did not show significant association, there was a trend towards association of low levels of HDL-C and T2DM occurrence (Table 3).
In the surveyed population (Phase 2) the mean levels of triglycerides and LDL-C were significantly higher in diabetics $(1.87 ; 1.35)$ compared to individuals with prediabetes $(1.63 ; 1.26)$ and unaffected controls $(1.49 ; 1.19)$ (Table 5). People with T2DM showed a significant decrease in HDL-C levels (Table 5). A strong correlation of overall hyperlipidemia with the diabetes affection status was shown $(\mathrm{p}<0.0001)$ (Table 6). Other comorbid factors such as hypertension $(\mathrm{p}<0.0001)$ and self-reported obesity ( $\mathrm{p}<0.0001$ ) were highly associated with T2DM and prediabetes (Table 6). Although cardiovascular disease status did not show significant results, there was a positive trend $(\mathrm{p}=0.08)$ (Table 6).

Triglycerides mean was significantly higher in patients with severe CAD compared to patients with mild CAD as well as healthy unaffected individuals (Table 2). Overall hyperlipidemia was associated with CAD ( $\mathrm{p}<0.0001)$. Low levels of HDL-C were associated with a severe CAD affection status $(\mathrm{p}=0.02)$ (Table 2). 
Table 2 Distribution in 991 individuals from FGENTCARD of different factors by CAD diagnosis status

\begin{tabular}{|c|c|c|c|c|c|}
\hline & & CAD cate & & & \\
\hline & Severe CAD $n=406$ & Mild CAD $n=207$ & Healthy $n=378$ & Total $n=991$ & $p$ value \\
\hline & No. (\%) & No. (\%) & No. (\%) & & \\
\hline Gender & & & & & 0.5 \\
\hline Male & $153(37.7)$ & $68(32.9)$ & $132(34.9)$ & & \\
\hline Female & $253(62.3)$ & $139(67.1)$ & $246(65.1)$ & & \\
\hline Age (years) mean (SD) & $64(11.3)$ & $66(9.9)$ & $64(10.5)$ & & 0.04 \\
\hline Body mass index, mean (SD) & $29.1(5.3)$ & $29.7(5.9)$ & $29.7(5.8)$ & & 0.2 \\
\hline Exercise activity level & & & & & 0.002 \\
\hline Non-active & $85(21.0)$ & $34(16.5)$ & $49(13.1)$ & & \\
\hline Moderate activity & $315(77.8)$ & $163(79.1)$ & 307 (81.9) & & \\
\hline Heavy activity & $5(1.2)$ & $9(4.4)$ & $19(5.1)$ & & \\
\hline Smoking & & & & & 0.01 \\
\hline Never smoker & $150(37.0)$ & $103(49.8)$ & $185(49.1)$ & & \\
\hline Former smoker & $105(25.9)$ & $43(20.8)$ & $81(21.5)$ & & \\
\hline Current smoker & $150(37.0)$ & $61(29.5)$ & $114(29.4)$ & & \\
\hline Family history of CAD & & & & & \\
\hline Yes & $260(64.5)$ & $91(44.2)$ & $174(46.3)$ & & 0.006 \\
\hline No & $143(35.5)$ & $115(55.8)$ & $202(53.7)$ & & \\
\hline Consanguinity & & & & & 0.44 \\
\hline Yes & $73(19.6)$ & $34(17.2)$ & $60(16.7)$ & & \\
\hline No & $299(80.3)$ & $163(82.7)$ & 299 (83.3) & & \\
\hline Hypertension & & & & & 0.1 \\
\hline Yes & $263(64.8)$ & $137(66.2)$ & $220(58.5)$ & & \\
\hline No & $143(35.2)$ & $70(33.8)$ & $156(41.5)$ & & \\
\hline Hyperlipidemia & & & & & $<0.0001$ \\
\hline Yes & $227(56.0)$ & $91(44.0)$ & $149(39.5)$ & & \\
\hline No & $178(44.0)$ & $116(56.0)$ & $228(60.5)$ & & \\
\hline Type 2 diabetes mellitus & & & & & $<0.0001$ \\
\hline Yes & $172(42.4)$ & $59(28.5)$ & $84(22.3)$ & & \\
\hline No & $234(57.6)$ & $148(71.5)$ & $292(77.7)$ & & \\
\hline
\end{tabular}

Abbreviation: CAD Coronary artery disease, SD Standard deviation.

Both triglycerides and overall hyperlipidemia were significantly associated with the diabetes status in the 1330 stenosis free group (Table 3). Subjects with T2DM showed a trend towards a decrease in HDL-C levels although this did not reach the level of significance (Table 3). A strong correlation of other comorbid factors such as hypertension $(\mathrm{p}<0.0001)$ and obesity $(\mathrm{p}<0.0001)$ were highly associated with T2DM (Table 3 ).

Studying reproductive health of women in the surveyed population showed a strong correlation between giving birth to a baby with a high weight and the occurrence of T2DM and prediabetes later in life $(\mathrm{p}<0.0001)$ (Table 7). Retinopathy and peripheral neuropathy were significantly correlated with diabetes and prediabetes $(\mathrm{p}<0.0001)$
(Table 8). We calculated the odds ratios of T2DM versus CAD in our T2DM (998 subjects) and CAD (991 subjects) groups. Figure 1 and Table 9 present an inferred risk of the major T2DM and CAD risk factors such as physical activity, smoking, BMI, HDL-C levels, hyperlipidemia, positive family history, and hypertension. The 1,330 stenosis free subjects replicated and confirmed the inferred risk of the factors found to increase T2DM in our surveyed population, such as BMI, triglycerides, overall hyperlipidemia, positive family history of T2DM, and hypertension. The protective role of physical activity against T2DM was also confirmed (Table 9).

Population enrollment shows significant association with T2DM diagnosis $(\mathrm{OR}=1.41,95 \% \mathrm{CI}: 1.22-1.62$, $\mathrm{p}$-value $=$ 
Table 3 Distribution in 1,330 random FGENTCARD individuals of different factors by T2DM diagnosis status

\begin{tabular}{|c|c|c|c|c|}
\hline & \multicolumn{4}{|c|}{ T2DM categories } \\
\hline & $\begin{array}{l}\text { Diabetic } \\
\mathrm{n}=\mathbf{2 7 2}\end{array}$ & $\begin{array}{c}\text { Non-diabetic } \\
n=1,058\end{array}$ & $\begin{array}{c}\text { Total } \\
n=1,330\end{array}$ & $p$ value \\
\hline & No. (\%) & No. (\%) & & \\
\hline Gender & & & & 0.008 \\
\hline Male & $121(44.5)$ & $566(53.5)$ & & \\
\hline Female & $151(55.5)$ & $492(46.5)$ & & \\
\hline $\begin{array}{l}\text { Age (years) } \\
\text { mean (SD) }\end{array}$ & $58(11.6)$ & $55(11.9)$ & & 0.0002 \\
\hline Body mass index & & & & $<0.0001$ \\
\hline Less than 30 & $111(42.2)$ & $645(62.6)$ & & \\
\hline More or equal to 30 & $152(57.8)$ & $385(37.4)$ & & \\
\hline Exercise activity level & & & & 0.007 \\
\hline Non-active & $41(15.1)$ & $93(8.8)$ & & \\
\hline Moderate activity & $214(79)$ & $886(83.7)$ & & \\
\hline Heavy activity & $16(5.9)$ & $79(7.5)$ & & \\
\hline Smoking & & & & 0.001 \\
\hline Never smoker & $143(52.6)$ & $433(40.9)$ & & \\
\hline Former smoker & $52(19.1)$ & $200(18.9)$ & & \\
\hline Current smoker & $77(28.3)$ & $425(40.2)$ & & \\
\hline \multicolumn{5}{|l|}{$\begin{array}{l}\text { Family history } \\
\text { of T2DM }\end{array}$} \\
\hline Yes & $190(69.9)$ & $492(46.5)$ & & $<0.0001$ \\
\hline No & $82(30.1)$ & $565(53.5)$ & & \\
\hline Consanguinity & & & & 0.6 \\
\hline Yes & $56(21.2)$ & $201(19.7)$ & & \\
\hline No & $208(78.8)$ & $818(80.3)$ & & \\
\hline \multicolumn{5}{|l|}{ Triglycerides } \\
\hline High level & $162(68.4)$ & $505(54.9)$ & & 0.0002 \\
\hline Normal level & 75 (31.6) & $415(45.1)$ & & \\
\hline HDL-cholesterol & & & & 0.6 \\
\hline Low level & $73(30.7)$ & $267(29.0)$ & & \\
\hline Normal level & $165(69.3)$ & $654(71.0)$ & & \\
\hline Hypertension & & & & $<0.0001$ \\
\hline Yes & $197(72.4)$ & $487(46.0)$ & & \\
\hline No & $75(27.6)$ & $571(54.0)$ & & \\
\hline Hyperlipidemia & & & & $<0.0001$ \\
\hline Yes & $213(78.6)$ & $659(62.3)$ & & \\
\hline No & $58(21.4)$ & $398(37.7)$ & & \\
\hline $\begin{array}{l}\text { Family history of } \\
\text { CAD }\end{array}$ & & & & 0.3 \\
\hline Yes & $144(53.1)$ & $602(57.0)$ & & \\
\hline No & $127(46.9)$ & $455(43.0)$ & & \\
\hline
\end{tabular}

Abbreviation: T2DM Type 2 diabetes mellitus, CAD Coronary artery disease; SD Standard deviation.
Table 4 Distribution of the different populations studied by T2DM diagnosis status

\begin{tabular}{|c|c|c|c|}
\hline & Diabetic (\%) & Non-diabetic (\%) & Total \\
\hline Surveyed T2DM population & $407(41)$ & $586(59)$ & 993 \\
\hline FGENTCARD population & $2,437(33.4)$ & $4,855(66.5)$ & 7,292 \\
\hline $\begin{array}{l}\text { Randomly selected } \\
\text { population }\end{array}$ & $272(20.5)$ & $1,058(79.5)$ & 1,330 \\
\hline $\begin{array}{l}\text { Randomly selected population } \\
\text { (age } \geq 55 \text { years old) }\end{array}$ & $157(23.6)$ & $507(76.4)$ & 664 \\
\hline CAD population & $2,152(36.5)$ & $3,748(63.5)$ & 5,900 \\
\hline
\end{tabular}

$1.73 \times 10^{-6}$ ) where $42 \%$ of the case-control selected T2DM enrollees had a T2DM diagnosis, while $34 \%$ of the CAD study enrollees had T2DM. On the other hand, there is a significant inverse association of CAD diagnosis with enrollment in the T2DM study $(\mathrm{OR}=$ $0.26,95 \%$ CI: $0.19-0.36$, p-value $<2 \times 10^{-16}$ ).

Results for variables such as hypertension, obesity and hyperlipidemia showed different levels of significant association with population enrollment in T2DM and CAD cohorts (Additional file 1).

Prediction of T2DM by metabolic syndrome variables, without or with inclusion of population for adjustment: hypertension (without: $\mathrm{OR}=1.61,95 \% \mathrm{CI}$ : $1.42-1.83$, $\mathrm{p}$-value $=2.31 \times 10^{-13}$; with: $\mathrm{OR}=1.75,95 \%$ CI: $1.54-2.00$, p-value $<2 \times 10^{-16}$ ), hyperlipidemia (without: $\mathrm{OR}=1.53,95 \%$ CI: $1.35-1.72$, p-value $=3.33 \times 10^{-12}$; with: $\mathrm{OR}=1.52,95 \%$ CI: $1.35-1.71$, p-value $=7.63 \times 10^{-12}$ ), triglycerides (without: $\mathrm{OR}=1.49,95 \%$ CI: $1.30-1.71$, p-value $=7.82 \times 10^{-9}$; with: $\mathrm{OR}=1.48,95 \%$ CI: $1.29-1.70$, p-value $=2.08 \times 10^{-8}$ ), BMI (without: $\mathrm{OR}=1.17,95 \%$ CI: $1.03-1.32$, p-value $=0.0127$; with: $\mathrm{OR}=1.19,95 \% \mathrm{CI}: 1.05-1.35$, p-value $=0.00515$ ), and gender (without: $\mathrm{OR}=1.06,95 \% \mathrm{CI}: 0.94-1.20$, $\mathrm{p}$-value $=0.322$; with: $\mathrm{OR}=0.94,95 \% \mathrm{CI}: 0.82-1.07$, $\mathrm{p}$-value $=0.332$.

Prediction of CAD by metabolic syndrome variables computed in a single regression, without or with inclusion of population for adjustment: T2DM (without: $\mathrm{OR}=1.85$, $95 \%$ CI: $1.51-2.27$, p-value $=2.45 \times 10^{-9}$; with: $\mathrm{OR}=1.97$, 95\% CI: $1.61-2.43$, p-value $\left.=9.46 \times 10^{-11}\right)$, hypertension (without: $\mathrm{OR}=1.41,95 \%$ CI: $1.17-1.70, \mathrm{p}$-value $=2.73 \times$ $10^{-4}$; with: $\mathrm{OR}=1.42,95 \% \mathrm{CI}: 1.17-1.71, \mathrm{p}$-value $=$ $2.63 \times 10^{-4}$ ), hyperlipidemia (without: $\mathrm{OR}=1.52,95 \%$ CI: $1.27-1.82$, p-value $=4.98 \times 10^{-6}$; with: $\mathrm{OR}=1.56,95 \%$ CI: $1.30-1.86$, p-value $=1.49 \times 10^{-6}$ ), triglycerides (without: $\mathrm{OR}=1.08,95 \%$ CI: $0.87-1.34$, p-value $=0.471$; with: $\mathrm{OR}=1.09,95 \%$ CI: $0.88-1.36, \mathrm{p}$-value $=0.414)$, BMI (without: $\mathrm{OR}=0.87,95 \%$ CI: $0.73-1.04$, p-value $=0.132$; with: $\mathrm{OR}=0.86,95 \% \mathrm{CI}: 0.72-1.03$, p-value $=0.107$ ), and gender (without: $\mathrm{OR}=0.26,95 \% \mathrm{CI}: 0.22-1.31$, p-value $<2 \times 10^{-16}$; with: $\mathrm{OR}=0.27,95 \% \mathrm{CI}: 0.22-0.32$, p-value $=<2 \times 10^{-16}$ ). 
Table 5 Lipid profile of the surveyed population by T2DM diagnosis status

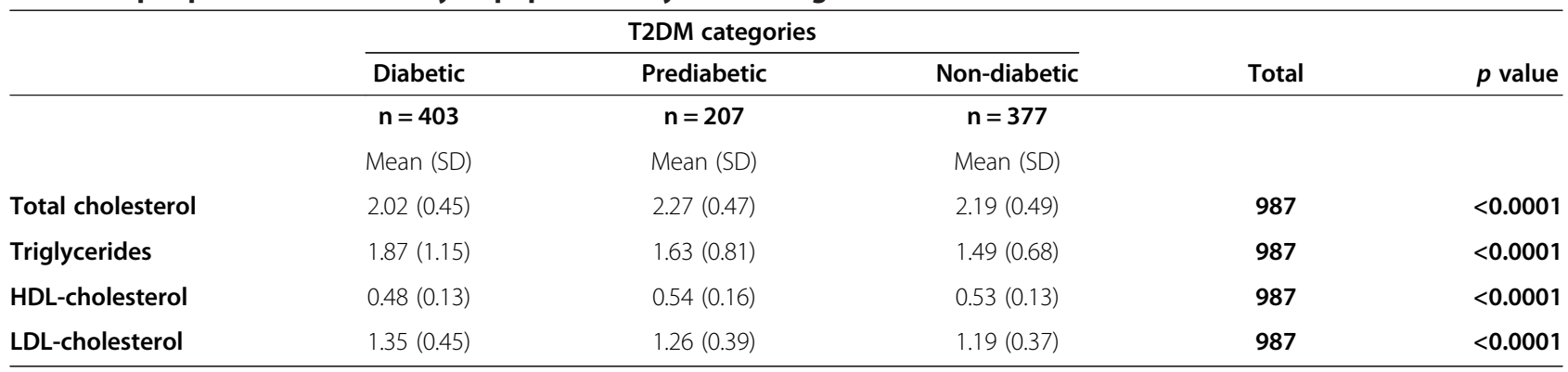

Abbreviation: T2DM type 2 diabetes mellitus, SD Standard deviation.

\section{Discussion}

Much about the pathology of T2DM and its etiology remains unknown. Researchers acknowledge that different genes and environmental factors may lead to disease processes that differ from person to person and from an environment to another. This study unravels some of the key environmental and behavioral factors that play a role in T2DM occurrence in the Lebanese population.

\section{Prevalence of T2DM and prediabetes}

The small number of males in the survey sample (35.6\%) was due to the fact that most men were at work at the time of the recruitment. In the randomly selected population, $51.7 \%$ of the participants were male compared to 48.3 females. Our surveyed population consisted of $40.8 \%$ diabetics, $20.7 \%$ of people with prediabetes, and $38 \%$ of unaffected healthy participants. The overestimation of affected people is probably due to the fact that campaigns were organized mainly with the help of endocrinologists for increasing T2DM awareness. Thus, people who knew they were affected and people with a positive family history had a higher interest in participating. This led us to investigate a population of 1,330 stenosis free participants from the FGENTCARD database. Although the prevalence of T2DM was not as high as in our surveyed population, it was $20.5 \%$ (Table 4 ). This confirms that Lebanon is facing an alarming increase of the prevalence of T2DM. This prevalence increased to $23.6 \%$ when we investigated control subjects that were above 55 years of age.

The prevalence of prediabetes was studied in the surveyed population only, as the information was not collected for the FGENTCARD participants. In the Lebanese population, the prevalence of prediabetes mirrors roughly the international tendency since approximately one in three U.S. citizens are known to have prediabetes [5]. Nearly $100 \%$ of the participants accurately self-reported T2DM and only $16 \%$ reported being aware of their pre-affection status (Table 10). These results indicate as expected that almost all individuals with T2DM were aware of their affection status, but alarmingly show that only one in six individuals had a prior knowledge of their prediabetes status. Awareness of prediabetes

Table 6 Distribution of comorbid factors in the surveyed population by T2DM diagnosis status

\begin{tabular}{|c|c|c|c|c|c|}
\hline & \multicolumn{3}{|c|}{ T2DM categories } & \multirow[b]{2}{*}{ Total } & \multirow[b]{2}{*}{$p$ value } \\
\hline & Diabetic & Prediabetic & Non-diabetic & & \\
\hline & No. (\%) & No. (\%) & No. (\%) & & \\
\hline Hypertension & & & & 961 & $<0.0001$ \\
\hline Yes & $226(56.6)$ & $97(47.5)$ & $139(38.8)$ & & \\
\hline No & $173(43.4)$ & $107(52.5)$ & $219(61.2)$ & & \\
\hline Hyperlipidemia & & & & 945 & $<0.0001$ \\
\hline Yes & $222(56.1)$ & $99(48.8)$ & $133(38.4)$ & & \\
\hline No & $174(43.9)$ & $104(51.2)$ & $213(61.6)$ & & \\
\hline Obesity & & & & 946 & $<0.0001$ \\
\hline Yes & $142(36.0)$ & $45(22.2)$ & $62(17.8)$ & & \\
\hline No & $252(64.0)$ & $158(77.8)$ & $287(82.2)$ & & \\
\hline Cardiac disease & & & & 952 & 0.08 \\
\hline Yes & $93(23.4)$ & $37(18.2)$ & $60(17.1)$ & & \\
\hline No & 305 (76.6) & $166(81.8)$ & $291(82.9)$ & & \\
\hline
\end{tabular}

Abbreviation: T2DM Type 2 diabetes mellitus. 
Table 7 Data on reproductive health of females in the surveyed T2DM and prediabetes populations

\begin{tabular}{|c|c|c|c|c|c|}
\hline & & T2DM catego & & & \\
\hline & Diabetic & Prediabetic & Non-diabetic & Total & $p$ value \\
\hline & No. (\%) & No. (\%) & No. (\%) & & \\
\hline Gestational diabetes & & & & 484 & 0.3 \\
\hline Yes & $9(4.3)$ & $2(1.9)$ & $3(1.8)$ & & \\
\hline No & $199(95.7)$ & $105(98.1)$ & $166(98.2)$ & & \\
\hline Baby weighing $>4$ kgs at birth & & & & 475 & $<0.0001$ \\
\hline Yes & $75(37.3)$ & $26(23.9)$ & $28(17.0)$ & & \\
\hline No & $126(62.7)$ & $83(76.1)$ & $137(83.0)$ & & \\
\hline Polycystic ovary syndrome & & & & 544 & 0.3 \\
\hline Yes & $9(3.9)$ & $6(4.8)$ & $14(7.4)$ & & \\
\hline No & $222(96.1)$ & $118(95.2)$ & $175(92.6)$ & & \\
\hline
\end{tabular}

Abbreviation: T2DM Type 2 diabetes mellitus.

should be promoted on the national level as persons with prediabetes are at high risk for developing T2DM and $11 \%$ of persons with prediabetes who do not engage in moderate physical activity and do not lose weight will progress to T2DM [6].

\section{Young onset of type 2 diabetes}

A feature characterizing T2DM in the Lebanese population is the tendency to develop young onset diabetes. A multiethnic population-based cohort from Canada noted that the median age at diagnosis of diabetes was lower by 3 years in Chinese compared to Caucasians ( 55 years vs. 58 years) [7]. In our surveyed population the mean age of onset of T2DM was of 55 years and thus 3 years less than the median age at diagnosis in Caucasians, although it is still higher than the mean age of diagnosis of T2DM in East Asia that is typically around 50 years (Table 1) [8]. The young age at diagnosis may be due to an increasingly overweight population as well as the rise in caloric and fat intake in a region where exercise is not a defining part of the culture [9].

\section{Reproductive health of females and intrauterine environment}

Once diagnosed with gestational diabetes mellitus, women are seven times more likely to develop T2DM during their lifetime compared with women without GDM history [10]. Because the information about GDM is largely missing in our cohort, we investigated the number of women who gave birth to a baby weighing more than 4 kilograms (9 pounds), since GDM and hyperglycemia in pregnancy have long been related to excessive fetal growth [11-14].

Table 8 Distribution of reported health complications in the surveyed population by T2DM diagnosis status

\begin{tabular}{|c|c|c|c|c|c|}
\hline & \multicolumn{3}{|c|}{ T2DM categories } & \multirow[b]{2}{*}{ Total } & \multirow[b]{2}{*}{$p$ value } \\
\hline & Diabetic & Prediabetic & Non-diabetic & & \\
\hline & No. (\%) & No. (\%) & No. (\%) & 944 & 0.0008 \\
\hline \multicolumn{6}{|l|}{ Retinopathy } \\
\hline Yes & $41(10.4)$ & $10(5.0)$ & $13(3.7)$ & & \\
\hline No & $354(89.6)$ & $192(95.0)$ & $334(96.3)$ & & \\
\hline Peripheral neuropathy & & & & 944 & 0.005 \\
\hline Yes & $61(15.5)$ & $25(12.3)$ & $27(7.8)$ & & \\
\hline No & $332(84.5)$ & $178(87.7)$ & $321(92.2)$ & & \\
\hline Liver disease & & & & 948 & 0.4 \\
\hline Yes & $18(4.5)$ & $5(2.5)$ & $11(3.2)$ & & \\
\hline No & $378(95.5)$ & $198(97.5)$ & $338(96.8)$ & & \\
\hline Skin condition* & & & & 948 & 0.6 \\
\hline Yes & $17(4.3)$ & $7(3.4)$ & $10(2.9)$ & & \\
\hline No & $380(95.7)$ & $196(96.6)$ & $338(97.1)$ & & \\
\hline
\end{tabular}

*Skin condition includes eleven psoriasis, six fungal infections, five dark spots on the skin, three vitiligo cases, three eczema, two lichen planus rashes, two back lipomas, and two itchy eruption of the skin. Abbreviation: T2DM Type 2 diabetes mellitus. 


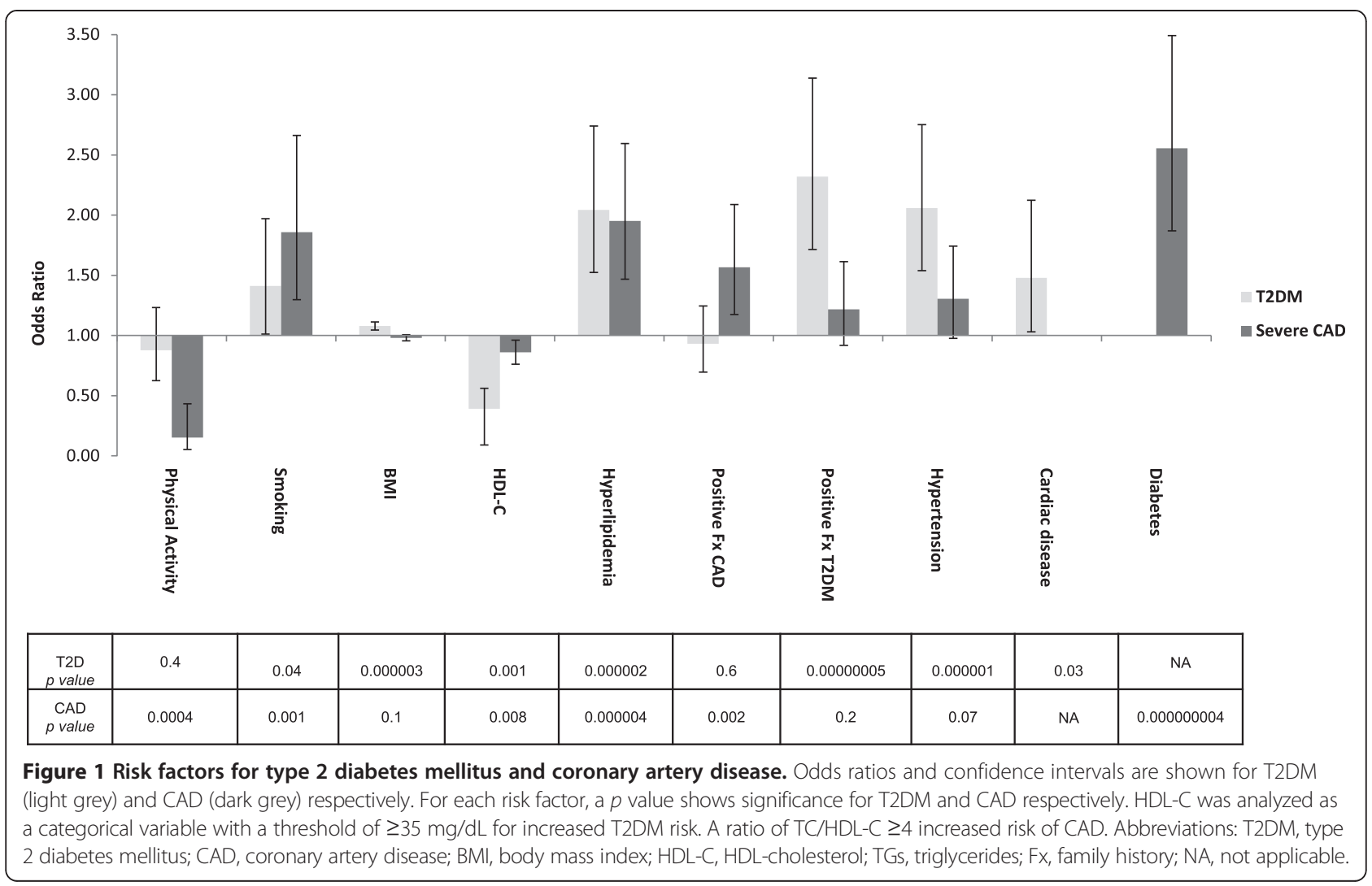

The link between birth weight and adult risk of T2DM has been observed in our cohort making it a general statement across different ethnicities. This is of particular concern since a comparison to offspring of normoglycemic mothers shows that offspring of mothers with GDM have increased adiposity at birth and increased risk of diabetes and obesity later in life [15,16]. Given the potential transgenerational effects of maternal hyperglycemia, GDM screening, diagnosis and treatment should be routinely practiced in the Lebanese hospitals.

\section{Lifestyle environmental and comorbid risk factors}

When participants from the surveyed population were asked about their weight, $26.3 \%$ admitted to be overweighed while $73.7 \%$ estimated not to have excess weight (Table 10). BMI measures showed that significantly more participants were overweight than what is self-reported with only $23.5 \%$ of the participants having normal weight, $37.1 \%$ and $30.1 \%$ being overweighed and obese respectively. BMI measures showed a significant association of overweight and obesity with diabetes. Physical activity was less frequent in diabetics compared to healthy participants but did not show statistically significant association with T2DM. The protective role of physical activity, as well as the association of a BMI $\geq 30$ with T2DM were further confirmed in our stenosis free population underlining the increased risk of disease occurrence in the Lebanese population. These findings highlight the urgent need for timely interventions promoting physical activity and weight control nationwide since Lebanon shows high prevalence of overweight and obesity comparable with those observed in developed countries [17].

Positive family history of T2DM was one of the most significant factors predisposing to diabetes occurrence in our study population underscoring the need for screening in individuals with family history. One of the reasons to screen for diabetes is that it has an asymptomatic phase for which screening can be helpful in preventing major health problems in a sizable portion of the population [18].

Hypertension was positively associated with diabetes in the different cohorts. Since both hypertension and T2DM affect the same major target vascular tree, lowering blood pressure should be the primary goal in the management of the hypertensive diabetic patients. Comorbid factors such as hyperlipidemia and low $H D L-C$ levels increased the risk of T2DM. T2DM is known to be associated with plasma lipid and lipoprotein abnormalities, including reduced HDL-C, and elevated triglycerides [19]. Prediabetics also exhibit an atherogenic pattern of risk factors that includes higher levels of TC, LDL-C, and triglycerides and lower levels of HDL-C $[20,21]$. These plasma lipid and lipoprotein associated abnormalities contribute to the risk for atherosclerosis in the majority of patients with type 2 diabetes [22]. Although we reproduced the positive 
Table 9 Unadjusted OR of association of selected risk factors

\begin{tabular}{|c|c|c|c|c|c|c|c|c|c|}
\hline & \multicolumn{3}{|c|}{ T2DM $(n=998)$} & \multicolumn{3}{|c|}{ Severe CAD $(n=991)$} & \multicolumn{3}{|c|}{ T2DM $(n=1,330)$} \\
\hline & OR & $95 \% \mathrm{Cl}$ & $p$ value & OR & $95 \% \mathrm{Cl}$ & $p$ value & OR & $95 \% \mathrm{Cl}$ & $p$ value \\
\hline \multicolumn{10}{|c|}{ Physical activity (Ref: Inactive people) } \\
\hline Active people & 0.88 & $0.62-1.23$ & 0.4 & 0.15 & $0.05-0.43$ & 0.0004 & 0.46 & $0.24-0.88$ & 0.02 \\
\hline Moderately active people & 1.1 & $0.66-1.83$ & 0.7 & 0.59 & $0.40-0.87$ & 0.008 & 0.55 & $0.37-0.81$ & 0.003 \\
\hline \multicolumn{10}{|l|}{ Smoking (Ref: Non-smokers) } \\
\hline Current Smoker & 1.41 & $1.01-1.97$ & 0.04 & 1.86 & $1.30-2.66$ & 0.001 & 0.55 & $0.40-0.75$ & 0.0001 \\
\hline Ex-Smokers & 1.4 & $0.96-2.02$ & 0.08 & 1.23 & $0.73-2.08$ & 0.4 & 0.79 & $0.55-1.13$ & 0.2 \\
\hline \multicolumn{10}{|l|}{ BMI (Ref: < 30) } \\
\hline$\geq 30$ & 1.08 & $1.04-1.11$ & $<0.0001$ & 0.98 & $0.95-1.01$ & 0.1 & 2.29 & $1.74-3.02$ & $<0.0001$ \\
\hline \multicolumn{10}{|c|}{ HDL-cholesterol (Ref: Healthy) } \\
\hline Yes & 0.39 & $0.22-0.69$ & 0.001 & 0.86 & $0.76-0.96$ & 0.01 & 1.08 & $0.79-1.48$ & 0.6 \\
\hline \multicolumn{10}{|l|}{ Triglycerides (Ref: Healthy) } \\
\hline Yes & 1.66 & $1.37-2.00$ & $<0.0001$ & 1 & $1.00-1.01$ & 0.001 & 1.78 & $1.31-2.40$ & 0.0002 \\
\hline \multicolumn{10}{|c|}{ Hyperlipidemia (Ref: Healthy) } \\
\hline Yes & 2.04 & $1.52-2.74$ & $<0.0001$ & 1.95 & $1.47-2.59$ & $<0.0001$ & 2.22 & $1.62-3.04$ & $<0.0001$ \\
\hline \multicolumn{10}{|c|}{ Family history of CAD (Ref: No family history of CAD) } \\
\hline Yes & 0.93 & $0.70-1.25$ & 0.6 & 1.57 & $1.17-2.09$ & 0.002 & 0.86 & $0.66-1.12$ & 0.3 \\
\hline \multicolumn{10}{|c|}{ Family history of T2DM (Ref: No family history of T2DM) } \\
\hline Yes & 2.32 & $1.71-3.14$ & $<0.0001$ & 1.22 & $0.92-1.61$ & 0.2 & 2.66 & $2.00-3.54$ & $<0.0001$ \\
\hline \multicolumn{10}{|l|}{ Hypertension (Ref: Healthy) } \\
\hline Yes & 2.06 & $1.54-2.75$ & $<0.0001$ & 1.3 & $0.98-1.74$ & 0.07 & 3.08 & $2.30-4.12$ & $<0.0001$ \\
\hline \multicolumn{10}{|c|}{ Coronary artery disease (Ref: Healthy) } \\
\hline Yes & 1.48 & $1.03-2.12$ & 0.03 & NA & NA & NA & NA & NA & NA \\
\hline \multicolumn{10}{|c|}{ Type 2 diabetes mellitus (Ref: Healthy) } \\
\hline Yes & NA & NA & NA & 2.56 & $1.87-3.49$ & $<0.0001$ & NA & NA & NA \\
\hline
\end{tabular}

ORs are calculated among individuals having T2DM compared to non-diabetic and having severe CAD compared to no stenosis as outcome variables. Abbreviation: T2DM Type 2 diabetes mellitus, CAD Coronary artery disease, OR Odds ratio, BMI Body mass index, Ref Reference.

association of overall hyperlipidemia with T2DM in the stenosis free participants, HDL-C did not show a significant protective role, but rather a tendency towards lower levels in individuals with T2DM (Table 3).

In the surveyed sample, peripheral neuropathy and retinopathy were the two complications significantly associated with T2DM. This is expected since peripheral neuropathy, a common microvascular complication of diabetes [23], is often associated with concomitant retinopathy [24].

Table 10 Self-reported T2DM, prediabetes, and excess body weight in the surveyed population

\begin{tabular}{lccc}
\hline & $\begin{array}{c}\text { Reported } \\
\text { condition } \\
\text { No. (\%) }\end{array}$ & $\begin{array}{c}\text { Not reported } \\
\text { condition } \\
\text { No. (\%) }\end{array}$ & Total \\
\hline Self-reported T2DM & $405(42.2)$ & $555(57.8)$ & $\mathbf{9 6 0}$ \\
Self-reported prediabetes & $35(4.1)$ & $825(95.9)$ & $\mathbf{8 6 0}$ \\
Self-reported weight excess & $250(26.3)$ & $701(73.7)$ & $\mathbf{9 5 1}$ \\
\hline
\end{tabular}

Abbreviation: T2DM Type 2 diabetes mellitus.

\section{T2DM versus CAD}

There is a close relationship between T2DM and CAD since patients with T2DM have a two to four fold higher risk of a cardiovascular event with a faster progression when compared with non-diabetic patients [25]. Comparing our T2DM surveyed cohort to an age and sex-matched previously described Lebanese CAD cohort confirmed that the presence of cardiac disease increased the risk of T2DM by 1.48 fold, whereas T2DM increased the risk of severe CAD by 2.56 fold. Studying other known environmental risk factors confirmed that the risk of severe CAD is increased with sedentary life, smoking, decreased HDL-C level, hyperlipidemia, and positive CAD family history. Hence, there is a growing need to emphasize early and vigilant risk factor management in patients with T2DM and CAD to help reduce their morbidity and mortality.

Smoking correlates with hypertension in a generally surveyed population, including diabetics, but is anticorrelated among subjects that reached the stage of 
catheterization. Interactions of activity level and smoking variables and T2DM also show interactions between populations. This suggests that the course of progression and treatment leading to catheterization include behavior modifications impacting correlations between these populations.

Contrary to the behavioral variables, the prediction of both T2DM and CAD by metabolic syndrome variables appears to be unaffected by population, even though the proportions of these variables in the two populations are different.

While T2DM, as a part of the metabolic syndrome complex, is a strong predictor of CAD, the associations between behavioral contributions and disease are strongly impacted by progression of disease and treatment.

\section{Comparison with previous studies}

A previous study aimed to determine the prevalence of diagnosed and undiagnosed diabetes in Greater Beirut in 2005 [26]. From a total of 3,000 exclusively Lebanese citizens with a mean age of $55.5,11.3 \%$ were found to have previously diagnosed diabetes and $5.1 \%$ had undiagnosed diabetes. The combined prevalence of previously diagnosed and newly diagnosed diabetes was $15.8 \%$. In the U.S., $6.3 \%$ of the population had diabetes: $4.5 \%$ diagnosed and $1.8 \%$ undiagnosed [27]. The ratio of known to unknown diabetes obtained in the Lebanese study was similar to the one recognized in the U.S at that time. Our results show that the prevalence of diagnosed diabetes in Lebanon had a sharp increase (2.6 fold in the surveyed population and 1.5 fold for the randomly selected population) among people $\geq 55$ years old for both sexes. A comparable increase is seen in the U.S. where the prevalence of diagnosed diabetes increased 2.3 times from 1990 to 2010 [28]. This study provides evidence that there is a severe epidemic of diabetes including self-reported diagnosed and undiagnosed diabetes. These results underscore the urgent need for planning and delivering primary prevention to the Lebanese population.

\section{Conclusions}

In conclusion, our study evaluates the number of prediabetics, diagnosed and undiagnosed T2DM in a group of the Lebanese participants. It shows a significant role for BMI, and positive family history in the predisposition to prediabetes and T2DM. It confirms comorbid factors such as hypertension, hyperlipidemia, and low levels of HDL-C to be associated with an increased risk of prediabetes and T2DM. It shows the effect of the in utero environment on the risk of T2DM later in life and gives an overview of the complications of T2DM in the Lebanese population. It compares well known risk factors in T2DM and CAD occurrence measuring odds ratios, showing the link between these two diseases that could be partly determined by an unhealthy lifestyle habits as overweight and physical inactivity. The results suggest the need to further educate the general public about the risk factors, complications and severity of T2DM and CAD prior to the development of disease. Observed associations between behaviors and disease depend heavily on progression of disease and treatment. Specifically, more advanced CAD and T2DM subjects enrolled through catheterization tend to have a negative association with smoking than those enrolled through advertisement in the T2DM cohort. The strongest correlations, regardless of enrollment, were between metabolic syndrome and T2DM.

\section{Additional file}

Additional file 1: Collection of data and demographic characteristics. A questionnaire gathered data on each subject's demographic characteristics such as age, sex, marital status, origin, and parental consanguinity. Data on behavioral risks factors, smoking status, alcohol consumption and exercise pattern was also obtained. Results. Association of behavioral variables such as hypertension, smoking, obesity, and hyperlipidemia, with population enrollment

\section{Abbreviations}

T2DM: Type 2 diabetes mellitus; CAD: Coronary artery disease; IDF: International diabetes federation; MENA: Middle East and North Africa Region; GDM: Gestational diabetes mellitus; FGENTCARD: Functional genomic diagnostic tools for coronary artery disease; $\mathrm{HbA1C}$ : Glycated hemoglobin; FBS: Fasting blood sugar; BMI: Body mass index; TC: Total cholesterol; HDL-C: HDL-cholesterol; LDL-C: LDL-cholesterol; ADA: American diabetes association; SPSS: Statistical package for social sciences; OR: Odds ratio; SD: Size difference; Ref: Reference; NPRP: National priorities research program.

\section{Competing interests}

The authors declare that they have no competing interests.

\section{Authors' contributions}

MGS made substantial contributions to conception and design, acquisition, analysis and interpretation of data, and drafted the manuscript. MD participated to the statistical analysis and the manuscript revision. AKS and YAS helped collecting, encoding, and analyzing the data. FC and $\mathrm{MH}$ participated in data collection. $Y C, R N, R A$, and $A B A$ contributed to the discussion and reviewed the manuscript. YA and $\mathrm{KH}$ organized and advertised for the campaigns. DEP participated to the statistical analysis. HES contributed to the discussion and reviewed the manuscript. PAZ contributed to the study design, results interpretation, discussion, manuscript revision, and he gave final approval of the version to be published. All authors read and approved the final manuscript.

\section{Acknowledgements}

We thank the patients for agreeing to participate in the study. We thank Dr. Jihane Romanos, Dr. Bouchra Douaihy, and Mrs. Hana Sbeit for helping in the campaigns. We thank the dispensaire de la maison maronite de soins et d'hébergement- Ain El Remmaneh, Ehden Governmental Hospital - Ehden, Caritas Liban - Dahr el Ain, Lebanese Red Cross - Amioun, Saint Joseph dispensary - Zgharta, and dispensary of Kfarhabou -Donnieh for hosting the campaigns. This publication was made possible by a grant from the Qatar National Research Fund under its National Priorities Research program (NPRP) award number NPRP 09-215-3-049. Its contents are solely the responsibility of the authors and do not necessarily represent the official views of the Qatar National Research Fund.

\section{Author details}

${ }^{1}$ Lebanese American University, School of Medicine, Beirut 1102 2801, Lebanon. ${ }^{2}$ Shafallah Medical Genetics Center, Doha, Qatar. ${ }^{3}$ Centre Hospitalier du Nord-CHN, Zgharta, Lebanon. ${ }^{4}$ Bioinformatics and Pattern 
Discovery, IBM T. J. Watson Research Centre, Yorktown Hgts, NY 10598, USA. ${ }^{5}$ Department of Internal Medicine, American University of Beirut, Beirut, Lebanon. ${ }^{6}$ Harvard School of Public Health, Boston, MA 02215, USA

Received: 17 June 2014 Accepted: 8 August 2014

Published: 21 August 2014

\section{References}

1. International Diabetes Federation: Diabetes Atlas 5th edition. Brussels, Belgium: 2012. http://www.idf.org/diabetesatlas.

2. Hager J, Kamatani Y, Cazier JB, Youhanna S, Ghassibe-Sabbagh M, Platt DE, Abchee AB, Romanos J, Khazen G, Othman R, Badro DA, Haber M, Salloum AK, Douaihy B, Shasha N, Kabbani S, Sbeite H, Chammas E, el Bayeh H, Rousseau F, Zelenika D, Gut I, Lathrop M, Farrall M, Gauguier D, Zalloua PA: Genome-wide association study in a Lebanese cohort confirms PHACTR1 as a major determinant of coronary artery stenosis. PLoS One 2012, 7:e38663.

3. American Diabetes Association: Diagnosis and classification of diabetes mellitus. Diabetes Care 2010, 33(1):S62-69.

4. R Development Core Team: $R$ : a language and environment for statistical computing. Vienna, Austria: R Foundation for Statistical Computing; 2013. ISBN ISBN 3-900051-07-0

5. National Diabetes Fact Sheet: National estimates and general information on diabetes and prediabetes in the United States. Atlanta, GA: US Department of Health and Human Services, CDC; 2011. http://www.cdc.gov/diabetes/pubs/ factsheet $11 . h$ tm

6. Knowler WC, Barrett-Connor E, Fowler SE, Hamman RF, Lachin JM, Walker EA Nathan DM: Reduction in the incidence of type 2 diabetes with lifestyle intervention or metformin. N Engl J Med 2002, 346:393-403.

7. Chiu M, Austin PC, Manuel DG, Shah BR, Tu JV: Deriving ethnic-specific BMI cutoff points for assessing diabetes risk. Diabetes Care 2011, 34:1741-1748.

8. Ma RC, Chan JC: Type 2 diabetes in East Asians: similarities and differences with populations in Europe and the United States. Ann N Y Acad Sci 2013, 1281:64-91.

9. al-Mahroos F, al-Roomi K: Overweight and obesity in the Arabian Peninsula: an overview. J R Soc Promot Health 1999, 119:251-253.

10. Bellamy L, Casas JP, Hingorani AD, Williams D: Type 2 diabetes mellitus after gestational diabetes: a systematic review and meta-analysis. Lancet 2009, 373:1773-1779.

11. Catalano PM, Hauguel-De Mouzon S: Is it time to revisit the Pedersen hypothesis in the face of the obesity epidemic? Am J Obstet Gynecol 2011, 204:479-487.

12. Leikin EL, Jenkins JH, Pomerantz GA, Klein L: Abnormal glucose screening tests in pregnancy: a risk factor for fetal macrosomia. Obstet Gynecol 1987, 69:570-573.

13. Metzger BE, Lowe LP, Dyer AR, Trimble ER, Chaovarindr U, Coustan DR, Hadden DR, McCance DR, Hod M, Mclntyre HD, Oats JJ, Persson B, Rogers MS, Sacks DA: Hyperglycemia and adverse pregnancy outcomes. N Engl J Med 2008, 358:1991-2002.

14. Sacks DA: Etiology, detection, and management of fetal macrosomia in pregnancies complicated by diabetes mellitus. Clin Obstet Gynecol 2007, 50:980-989

15. Boney CM, Verma A, Tucker R, Vohr BR: Metabolic syndrome in childhood: association with birth weight, maternal obesity, and gestational diabetes mellitus. Pediatrics 2005, 115:e290-296.

16. Group HSCR: Hyperglycemia and adverse pregnancy outcome (HAPO) study: associations with neonatal anthropometrics. Diabetes 2009, 58:453-459.

17. Sibai AM, Hwalla N, Adra N, Rahal B: Prevalence and covariates of obesity in Lebanon: findings from the first epidemiological study. Obes Res 2003, 11:1353-1361

18. Valdez R: Detecting undiagnosed type 2 diabetes: family history as a risk factor and screening tool. J Diabetes Sci Technol 2009, 3:722-726.

19. Haffner SM: Management of dyslipidemia in adults with diabetes. Diabetes Care 2003, 26(Suppl 1):S83-86.

20. Haffner SM, Mykkanen L, Festa A, Burke JP, Stern MP: Insulin-resistant prediabetic subjects have more atherogenic risk factors than insulinsensitive prediabetic subjects: implications for preventing coronary heart disease during the prediabetic state. Circulation 2000, 101:975-980.

21. Haffner SM, Stern MP, Hazuda HP, Mitchell BD, Patterson JK: Cardiovascular risk factors in confirmed prediabetic individuals. Does the clock for coronary heart disease start ticking before the onset of clinical diabetes? JAMA 1990, 263:2893-2898.

22. Krauss RM: Lipids and lipoproteins in patients with type 2 diabetes. Diabetes Care 2004, 27:1496-1504.

23. Boulton AJ, Vinik Al, Arezzo JC, Bril V, Feldman EL, Freeman R, Malik RA, Maser RE, Sosenko JM, Ziegler D: Diabetic neuropathies: a statement by the American diabetes association. Diabetes Care 2005, 28:956-962.

24. Dyck PJ, Davies $J L$, Wilson DM, Service FJ, Melton LJ 3rd, O'Brien PC: Risk factors for severity of diabetic polyneuropathy: intensive longitudinal assessment of the Rochester Diabetic Neuropathy Study cohort. Diabetes Care 1999, 22:1479-1486.

25. Morrish NJ, Wang SL, Stevens LK, Fuller $\mathrm{HH}$, Keen $\mathrm{H}$ : Mortality and causes of death in the WHO multinational study of vascular disease in diabetes. Diabetologia 2001, 44(Suppl 2):S14-21.

26. Hirbli KI, Jambeine MA, Slim HB, Barakat WM, Habis RJ, Francis ZM: Prevalence of diabetes in greater Beirut. Diabetes Care 2005, 28:1262.

27. National Diabetes Fact Sheet: Total prevalence of diabetes in the United States. 2004. http://wwwcdcgov/diabetes/pubs/factsheethtm.

28. Centers for Disease Control and Prevention (CDC): Increasing prevalence of diagnosed diabetes-United States and Puerto Rico, 1995-2010. MMWR Morb Mortal Wkly Rep 2012, 61:918-921.

doi:10.1186/1758-5996-6-89

Cite this article as: Ghassibe-Sabbagh et al:: Multivariate epidemiologic analysis of type 2 diabetes mellitus risks in the Lebanese population. Diabetology \& Metabolic Syndrome 2014 6:89.

\section{Submit your next manuscript to BioMed Central and take full advantage of:}

- Convenient online submission

- Thorough peer review

- No space constraints or color figure charges

- Immediate publication on acceptance

- Inclusion in PubMed, CAS, Scopus and Google Scholar

- Research which is freely available for redistribution 